\title{
TỔNG QUAN TÌNH HİNH HOẠT ĐỘNG TRUNG TÂM TIM MẠCH BỆH VIỆN E SAU 17 THÁNG
}

\section{Lê Ngọc Thành và cộng sụ *}

\section{Tóm tắt}

Trong thời gian 17 tháng kể từ khi bắt đấu đi vào hoạt động ngày $24 / 2 / 2010$ trung tâm tim mạch đã mổ tổng số 1168 bệnh nhân, trong đó $1008 \mathrm{ca}$ tim hở (tỉ lệ tim bẩm sinh $56,4 \%$, mắc phải $43,6 \%$ ); 160 ca tim kín. Trung tâm đã phẫu thuật các bệnh lý tim mạch với nhiều thương tổn phối hợp: thương tổn van + mạch vành, thương tổn 3 van...; các kỹ thuật khó: sửa van, mở rộng vòng van, bắc cầu chủ vành tim đập ... đã được thực hiện; các bệnh tim bẩm sinh phức tạp: thất phải hai đường ra, tứ chứng Fallot trên bệnh nhân đảo ngược phủ tạng, hội chứng Shone, Ebstein, thông sàn nhĩ thất.... Bệnh nhân cao tuổi nhất 84 tuổi, nhỏ nhất 1,5 tháng, cân nặng thấp nhất $3,5 \mathrm{~kg}$. Hiện tại đã triển khai 2 bàn mổ cho phẫu thuật tim hở với số lượng 6 bệnh nhân/ngày; 1 bàn mổ cho phẫu thuật tim kín: các bệnh lý về phổi, trung thất, lồng ngực và mạch máu với các kỹ thuật mới đã được triển khai thành công (nội soi cắt $\mathrm{u}$ trung thất, cắt thùy phổi, nội soi nâng lõm xương ức...). Khoa tim trẻ em đã thành lập với định hướng phát triển trong thời gian tới mổ thường quy trẻ sơ sinh.

\section{SUMMARY}

Within 17 months from the beginning of its activities on Febuary 24th 2010, the Cardiovascular Center has operated on 1168 patients in total, including 1008 cases using CPB (of which 56,4 percent was congenital heart desease; 43,6 percent was acquired heart disease), and 101 cases without CPB. The Center has treated cardiovascular diseases with various associated lesions: valvular and coronary disease, Trivalvular disease...; difficult techniques: valve repair, annular enlargement, OPCABG... have been applied; complex congenital heart defects: DORV, TOF associated with situs inversus, Shone's syndrome, Ebstein, atrioventricular septal defect... The oldest patient was 84 years of age, the youngest was 1,5 months old, the lowest weight was $3,5 \mathrm{~kg}$. At present we are using 2 operating room for open heart surgery with the number of 6 cases per day; and 1 for closed heart surgery: pulmonary, mediastinal, thoracic and vascular diseases with new techniques successfully performed (endoscopic mediastinal tumorectomy, pulmonary lobectomy, pectus excavatum correction - Nuss procedure...). Our forthcoming direction is routine operation on neonates.

\section{I. Đặt vấn đề}

Đáp ứng nhu cầu bức thiết của xã hội về số lượng bệnh nhân tim mạch chờ mổ ngày càng tăng, ngày 26/8/2009 Bộ trưởng Bộ y tế đã ký quyết định thành lập Trung tâm Tim mạch. Chỉ trong một thời gian ngắn kể từ ngày $24 / 2 / 2010$ khi thủ tướng chính phủ về cắt băng khánh thành đến nay Trung tâm tim mạch đã phẫu thuật cho 1168 bệnh nhân mắc các bệnh lý về tim mạch và lồng ngực. Hầu hết các kỹ thuật chuyên khoa mới, các bệnh lý với thương tổn phức tạp, phối hợp đã được thực hiện. Cùng với các cơ sở phẫu thuật tim lớn khác trong cả nước, trung tâm tim mạch đã trở thành một địa chỉ tin cậy, uy tín cho người bệnh. Chúng tôi tổng kết 1168 ca phẫu thuật đầu tiên nhằm đánh giá hoạt động của trung tâm tim mạch trong thời gian 17 tháng kể từ khi hoạt động và hướng phát triển trong thời gian tới.

\section{Kết quả}

\section{1. Đặc điểm về tuổi, giới}

Bảng 1: Phân bố về giới

\begin{tabular}{lll}
\hline Giới & n & \% \\
\hline Nam & 576 & 49,3 \\
Nũ & 592 & 50,7 \\
\hline
\end{tabular}

\footnotetext{
* Trung tâm Tim mach Bệnh viện E
} 


\begin{tabular}{lll}
\hline Tuổi & n & \% \\
\hline$<6^{\text {th }}$ & 48 & 4,2 \\
6 th $-1 \mathrm{t}$ & 67 & 5,7 \\
$1-5$ & 152 & 13 \\
$5-15$ & 219 & 18,8 \\
$15-60$ & 573 & 49 \\
$>60$ & 109 & 9,3 \\
\hline
\end{tabular}

Tuổi trung bình: 31,7 22,6.Bệnh nhân nhỏ tuổi nhất: 1,5 tháng Tuổi cao nhất: 84

2. Phân bố về địa lý:

Bảng 3: Phân bố về địa lý

\begin{tabular}{llll}
\hline Tỉnh-Thành phố & $\%$ & Tỉnh Thành phố & $\%$ \\
\hline Hà Nội & 25 & Hưng Yên & 2,5 \\
Thái bình & 11 & Yên Bái & 0,9 \\
Hải Phòng & 7,4 & Tuyên Quang & 1,2 \\
Bắc Giang & 6,8 & Lạng Sơn & 1,7 \\
Quảng Ninh & 5,5 & Lào Cai & 0,6 \\
Thanh Hóa & 3,5 & Hòa Bình & 0,4 \\
Nghệ An & 3,8 & Cao Bằng & 0,4 \\
Nam Định & 3,8 & Sơn La & 0,9 \\
Phú Thọ & 3,5 & Bắc cạn & 0,1 \\
Thái Nguyên & 2,2 & Quảng trị & 0,1 \\
Hải Dương & 2,6 & Playku & 0,1 \\
Hà Nam & 3,5 & Đà Năng & 0,1 \\
Ninh Bình & 3,3 & Bình Phước & 0,1 \\
Bắc Ninh & 3,6 & & \\
Vĩnh phúc & 3,2 & & \\
Hà Tĩnh & 2,2 & & \\
\hline
\end{tabular}

Bệnh nhân đến từ hầu hết các tỉnh miền bắc và miền trung, trong đó Hà Nội chiếm tỷ lệ cao nhất.

3. Phân bố về bệnh:

3.1. Phẫu thuật tim hở: 1008 bệnh nhân

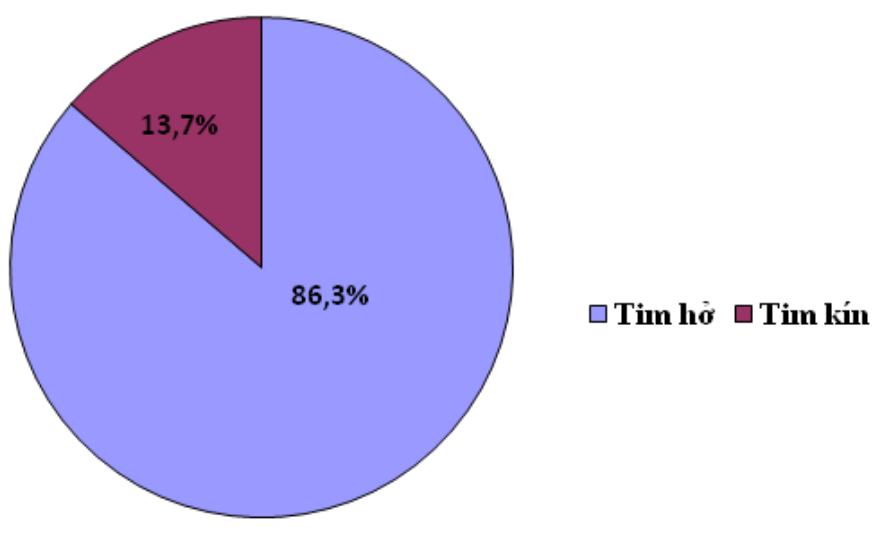

Biểu đồ 1: Tỷ lệ phẫu thuật tim hở - tim kín

3.1.1. Bệnh tim bẩm sinh (tim hở): 569 bệnh nhân 
Bảng 4: Các bệnh tim bẩm sinh

\begin{tabular}{lll}
\hline Bệnh tim bẩm sinh & $\mathbf{n}=\mathbf{5 6 9}$ & $\mathbf{\%}$ \\
\hline TLN & 79 & 13,9 \\
TLT & 347 & 60,95 \\
Tứ chứng Fallot & 63 & 11 \\
Thông sàn nhĩ thất & 20 & 3,6 \\
Thất phải hai đường ra & 9 & 1,6 \\
Ebstein & 2 & 0,4 \\
Hội chứng Shone & 5 & 0,8 \\
Phẫu thuật lại TLT tồn lưu & 1 & 0,15 \\
Rò Vành & 2 & 0,4 \\
Hẹp ĐRTP & 4 & 0,8 \\
TLT +Vỡ phình xoang valsalva & 6 & 0,9 \\
Cửa sồ Phế - Chủ & 1 & 0,15 \\
Đường hầm thất trái-ĐMC & 1 & 0,15 \\
Sửa van, eo ĐMC & 2 & 0,4 \\
TLN+TLT & 12 & 2,2 \\
Bất thường TM phổi toàn bộ & 5 & 0,8 \\
Tim bẩm sinh phức tạp & 10 & 1,8 \\
\hline
\end{tabular}

3.1.2. Bệnh tim mắc phải: 439 bệnh nhân

Bảng 5: Các bệnh tim mắc phải

\begin{tabular}{lll}
\hline Bệnh tim mắc phải & $\mathbf{n = 4 3 9}$ & $\mathbf{\%}$ \\
\hline Van hai lá & 260 & 59,2 \\
Van ĐMC & 44 & 10 \\
Van hai lá + ĐMC & 54 & 12,3 \\
Van HL + ĐMC + 3 lá & 14 & 3,2 \\
Hẹp vành & 50 & 11,3 \\
Van hai lá + Hẹp vành & 4 & 1 \\
Osler van hai lá & 2 & 0,5 \\
Osler van ĐMC & 2 & 0,5 \\
Osler van nhân tạo & 1 & 0,2 \\
Thay lại van & 3 & 0,7 \\
U nhây nhĩ trái & 3 & 0,7 \\
Hẹp vành+TLN & 1 & 0,2 \\
Van ĐMC + Hẹp vành & 1 & 0,2 \\
\hline
\end{tabular}

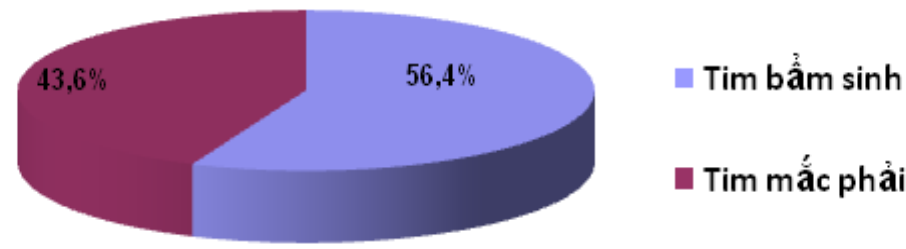

Biểu đồ 2: Tỷ lệ tim bẩm sinh-mắc phải 


\subsection{Phẫu thuật tim kín: 160 bệnh nhân}

Bảng 6: Các bệnh lý tim kín

\begin{tabular}{lll}
\hline Phẫu thuật tim kín & $\mathbf{n}=\mathbf{1 6 0}$ & $\mathbf{\%}$ \\
\hline U trung thất & 23 & 14,375 \\
U phổi & 26 & 16,25 \\
Cắt hạch giao cảm ngực & 3 & 1,875 \\
Kén khí màng phổi & 2 & 1,25 \\
U máu & 5 & 3,125 \\
Phồng ĐMC bụng & 6 & 3,75 \\
Lấy huyết khối mạch ngoại vi & 4 & 2,5 \\
Suy van tĩnh mạch hiển & 10 & 5,25 \\
Bướu giáp & 5 & 3,125 \\
Lõm xương ức & 8 & 5 \\
Tràn dịch màng tim(DL Marfan) & 15 & 9,375 \\
Còn ống động mạch & 22 & 13,75 \\
Hẹp eo động mạch chủ & 1 & 0,625 \\
Tạo shunt chạy thận nhân tạo & 6 & 3,75 \\
U cơ & 2 & 1,25 \\
Bắc cầu ĐM chậu - đùi & 4 & 2,5 \\
Máu cục màng phổi & 1 & 0,625 \\
Vết thương mạch đùi & 2 & 1,25 \\
U thành ngực & 2 & 1,25 \\
U góc hàm & 1 & 0,625 \\
Hẹp ĐM cảnh & 1 & 0,625 \\
Bắc cầu ĐM nách - đùi & 1 & 0,625 \\
Tắc ĐM đùi & 5 & 3,125 \\
Ố cặn màng phổi & 1 & 0,625 \\
U tuyến ức & 2 & 1,25 \\
Hẹp khí quản & 1 & 0,625 \\
Tách van ĐM phổi & 0,625 \\
\hline & & \\
& 1 & \\
\hline
\end{tabular}

\section{Cân nặng trong phẫu thuật tim bẩm sinh:}

Bảng 7: Cân nặng trong mổ tim bẩm sinh

\begin{tabular}{lll}
\hline Cân nặng & n & \% \\
\hline$<5 \mathrm{~kg}$ & 42 & 7,3 \\
$<10 \mathrm{~kg}$ & 135 & 23,7 \\
$>10 \mathrm{~kg}$ & 392 & 69 \\
\hline
\end{tabular}

Trẻ thấp cân nhất $3.0 \mathrm{~kg}$ 


\section{Tai biến, biến chứng:}

Bảng 8: Tai biến, biến chứng

\begin{tabular}{llll}
\hline Tai biến, biến chứng & n & $\%$ \\
\hline Chảy máu phải mổ lại & 5 & 0,5 \\
Viêm xương ức & 7 & 0,7 \\
Tràn dịch màng tim sau mổ ( phải dẫn lưu) & 10 & 1 \\
Tai biến thần kinh & 3 & 0,3 \\
Block nhĩ thất & 2 & 0,2 \\
Liệt hoành & & 1 & 0,1 \\
\hline Tử vong, nặng xin về (tim hở) & Thông sàn nhĩ thất & 1 & 0,1 \\
\multicolumn{1}{c}{$(15 / 1008: 1,48 \%)$} & Van hai lá & 3 & 0,3 \\
& Van hai lá - ĐMC & 2 & 0,2 \\
& Hẹp vành & 2 & 0,2 \\
& Fallot & 7 & 0,7 \\
\hline
\end{tabular}

Tỷ lệ tử vong, nặng xin về chung là 1,48 \%. Có 7 bệnh nhân nhiễm trùng xương ức được phẫu thuật nạo viêm, cả 7 đều ổn định ra viện. 2 trường hợp block nhĩ thất xảy ra trên bệnh nhân hội chứng Shone, phẫu thuật mở rộng đường ra thất trái và 1 bệnh nhân vá TLT. 2 bệnh nhân này được dặt máy tạo nhịp vĩnh viễn.

\section{Bàn luận}

Để đáp ứng nhu cầu người bệnh, với chủ chương của chính phủ, Bộ Y tể trung tâm tim mạch được thành lập với cơ sở vật chất và trang thiết bị hiện đại, đồng bộ. Đội ngũ phẫu thuật viên, gây mê hồi sức, nội khoa,... hầu hết được đào tạo một cách cơ bản, chính quy trong và ngoài nước, có nhiều thời gian, kinh nghiệm làm việc trong lĩnh vực phẫu thuật tim mạch ở cơ sở phẫu thật tim mạch lớn. Chính vì vậy chỉ trong một thời gian ngắn sau khi đi và hoạt động trung tâm tim mạch đã phẫu thuật cho một số lượng lớn bệnh nhân với hầu hết các bệnh lý bẩm sinh, mắc phải. Hiện nay, với số lượng 6 bệnh nhân tim hở/ngày trung tâm đã nhanh chóng trở thành một trong những cơ sở phẫu thuật tim mạch ngang tầm với các cơ sở khác trong cả nước.

Hiện tại trung tâm đã phẫu thuật cho bệnh nhân ở hầu hết các tỉnh miền bắc, miền trung với đủ mọi lứa tuổi. Đặc biệt với định hướng tập trung phát triển chuyên sâu,trung tâm đã thành lập khoa tim nhi và chủ trương thành lập đơn vị sơ sinh, chuẩn bị cho việc phẫu thuật tim sơ sinh. Với thành công trong việc hạ thấp cần nặng và độ tuổi phẫu thuật (trẻ nhỏ nhất 1,5 tháng, cân nặng thấp nhất $3.0 \mathrm{~kg}$ ) chúng tôi đã có những bước chuẩn bị tích cực về cả con người và phương tiện cho việc phẫu thuật tim sơ sinh trở thành thường quy.
Cùng với tim bẩm sinh, các bệnh lý tim mạch mắc phải: bệnh lý về van, mạch vành, động mạch chủ...đã được phẫu thuật thành công trên một số lượng lớn các bệnh nhân. Với sự phát triển của xã hội, mô hình bệnh tật của chúng ta sẽ dần dần tiến tới mô hình của các nước phát triển: độ tuổi ngày càng cao nhiều thương tổn phối hợp, phức tạp, nhất là bệnh lý mạch vành phối hợp với các thương tổn về van và động mạch chủ. Bệnh nhân cao tuổi nhất 84 tuổi được phẫu thuật cấp cứu bắc 5 cầu mạch vành, bệnh nhân phối hợp nhiều thương tổn được lấy huyết khối nhĩ trái, thay van hai lá, bắc cầu chủ vành ở tuổi 78 . Hiện nay các bệnh nhân thay van của chúng ta còn trong độ tuổi trẻ, trong tương lai sẽ phải thay lại van ở những đối tượng này. Chúng tôi đã phẫu thuật thay lại van cho bệnh nhân cao tuổi nhất 74 tuổi.

Bên cạnh phẫu thuật tim hở, trung tâm cũng chủ trương phát triển phẫu thuật bệnh lý mạch máu, lồng ngực. Các kỹ thuật mới về nội soi lồng ngực đã được thực hiện (cắt u trung thất, phổi, nâng lơm xương ức...). Cùng với Bệnh viện Việt Đức là cơ sở phẫu thuật lâu năm tại miền Bắc về mạch máu, trung tâm đã triển khai phẫu thuật các bệnh lý mạch máu ngoại vi.

Tỉ lệ tử vong, nặng xin về cũng như các rủi ro phẫu thuật, tỉ lệ nhiểm trùng ở trung tâm tương đối thấp. Điều này có được trước hết do đội ngũ nhân 
viên hầu hết là những người đã làm việc nhiều năm, có kinh nghiệm trong lĩnh vực phẫu thuật tim mạch. Mặt khác với sự đầu tư của nhà nước, trung tâm có cơ sở vật chất tốt, trang thiết bị hiện đại và đồng bộ, môi trường bệnh viện sạch đã tạo điều kiện hết sức thuận lợi cho việc nâng cao cả về số lượng và chất lượng phẫu thuật. Đặc biệt trong tương lai gần, với những đầu tư tiếp theo của chính phủ, chúng tôi sẽ triển khai tim mạch can thiệp.

Ngay từ khi thành lập, cùng với mục tiêu phát triển về kỹ thuật chuyên môn, trung tâm cũng đặt mục tiêu xây dựng chất lượng phục vụ, một vấn đề còn khá nổi cộm tại các cơ sở y tế công lập. Trung tâm tổ chức các lớp về giao tiếp cho nhân viên do chuyên gia có uy tín giảng dạy, đặc biệt chú trọng đào tạo đội ngũ điều dưỡng, hộ lý cả công việc chuyên môn cũng như về thái độ phục vụ người bệnh. Chúng tôi nhận thức rõ sự hài lòng của người bệnh sẽ gắn liền với sự phát triển của trung tâm. Qua một khảo sát nhỏ được thực hiện tại trung tâm, chúng tôi đã bước đầu đạt được mục tiêu đó.

\section{Kết luận}

- Trung tâm tim mạch đã nhanh chóng phát triển, trở thành cơ sở phẫu thuật tim mạch tin cậy đối với bệnh nhân. ... thấp

- Tỉ lệ tử vong, nhiễm trùng, rủi ro phẫu thuật

- Phát triển chuyên sâu từng lĩnh vực trong phẫu thuật tim mạch, nhất là đối với tim bẩm sinh, phẫu thuật sơ sinh là định hướng phát triển của trung tâm

- Tim mạch can thiệp cần được triển khai trong thời gian tới

Chất lượng phục vụ, sự hài lòng của người bệnh là yếu tố đặc biệt quan trọng cho sự phát triển của trung tâm 